\title{
WHAT BRINGS WOMEN INTO EHEALTH? WOMEN'S CAREER TRAJECTORIES IN DIGITAL TRANSFORMATIONS IN HEALTHCARE
}

\author{
Åsa Cajander ${ }^{1}$, Hilde G. Corneliussen ${ }^{2}$, Gunilla Myreteg ${ }^{3}$ and Kari Dyb ${ }^{4}$ \\ ${ }^{1}$ Uppsala University, Department of Information Technology, Lägerhyddsvägen 2, Uppsala, Sweden \\ ${ }^{2}$ Western Norway Research Institute, Box 163, 6851 Sogndal, Norway \\ ${ }^{3}$ Uppsala University, Department of Business Studies, Kyrkogårdsgatan 10, Uppsala, Sweden \\ ${ }^{4}$ Norwegian Centre for E-health Research, Sykehusveien 23, Troms $\phi$, Norway
}

\begin{abstract}
Digital transformation of health care services is addressed world-wide in order to more efficiently meet the patients' information and health care needs. However, little is known about the people working with this transformation, where two traditionally gendered fields meet; health care and IT. While work with digitalization generally is dominated by men, digitalization of health care services involves a large number of women. This case study explores the career trajectories of women working with the digital transformation of eHealth services. Who are the women in this eHealth project, and how did they come to working with this digital transformation? The analysis shows different types of trajectories that brought the women into eHealth transformations: The first illustrating women who were pushed into working with eHealth by their job descriptions, the second showing women using eHealth as an escape route from something else, and the last trajectory showing how women stumbled across eHealth and decided to stay on. This has implications for the educational system, and points to the need for being able to study computer science later in life. It also calls for a better understanding of what drives women in transformation processes.
\end{abstract}

\section{KEYWORDS}

Career Trajectories, Digital Transformation, Ehealth, Gender

\section{INTRODUCTION}

A digital transformation introducing eHealth into health care services has changed health care, and is also crucial to meet the challenges of the future with an ageing population and increased health care needs. Health care and ICT, however, are two highly gendered fields, in particular in the Nordic countries including Sweden. While only one in five ICT specialists were women in 2018 (Eurostat, 2019), women completely dominate health care professions numerically, for instance in nursing where about $90 \%$ are women (Socialstyrelsen, 2019). Ehealth requires competences from both health care and ICT, but since eHealth is still new to the educational field, few employees in health care have a special eHealth education. More research is needed about people working in eHealth generally, and we know very little about the women working in eHealth or how they are brought into this field. Hence this paper explores the career trajectories of women in an eHealth case study related to a digital transformation. Who are these women, how and why are they involved in this digital transformation?

The eHealth context of this study concerns the implementation of Patient Accessible Electronic Health Records (PAEHR) in Sweden. This was quite a controversial change process that started in the 1990's. The implementation included changes in national law and has been referred to as a paradigm shift in health care services that met strong opposition (Erlingsdottir et al., 2014; Erlingsdóttir and Lindholm, 2015, 2015; Hägglund and Scandurra, 2017). 
Ehealth services to patients are implemented globally to empower patients and make care more efficient (see for example Okun and Wicks, 2018; Walker et al., 2019). Sweden is an example of a country with a very ambitious agenda for the future. This involves the aim at being "best at" digitalisation (Regeringskansliet, 2017), and even "world leading" in eHealth services (Regeringskansliet, 2016). However, not all eHealth projects succeed and there are numerous studies describing problems with IT implementation (Hennemann et al., 2017). Often eHealth technology is perceived to be difficult to use by health care staff (Scandurra et al., 2014; Wass and Vimarlunda, 2018), and eHealth has had problems with user adoption (Dixon, 2007; Hoque et al., 2017), while studies also show a high satisfaction from patients. One should note that the problems related to eHealth implementation are not always technical in nature, but are also related to social challenges (Nilsson et al., 2016).

The Swedish national eHealth strategy states that "all residents from 16 years should by 2020 have access to all information documented in county-funded health and dental care" by 2025 (Regeringskansliet, 2016). However, when the eHealth service PAEHR was implemented in Sweden, it was quite controversial, and there were diverse reactions among the stakeholders (Cajander et al., 2018; Grünloh et al., 2018, 2016). With this service, patients could read their medical records notes from visits, test results, diagnosis, referrals, and a log listing health care staff who had read the electronic patient record (Moll et al. 2018). Many patients were in favour of PAEHR, and read their medical notes to keep informed and to be a part of the care process (Moll et al., 2018)), but clashes were experienced between the professional autonomy and patient empowerment (Erlingsdottir et al., 2014; Erlingsdóttir and Lindholm, 2015). Also, many health care professionals were worried about their work environment and the effects on patients when reading, for example, about cancer diagnosis online (Cajander et al., 2018; Cajander and Grünloh, 2019). Due to the political system in Sweden with autonomous regions there are local varieties to how the eHealth services are designed and implemented, both technically and organizationally. Hägglund and Scandurra (2017) describes this as that the "development and implementation of PAEHR in Sweden is based on local initiatives".

Previous research has established that the work environment in health care is problematic (Hsu, 2016). Alarming research shows that among young nurses, every fifth nurse strongly intended to leave the profession five years after graduation, and the intention was associated with levels of burnout (Rudman et al., 2014). Research has indicated that there is a lack of interest in care in the computing discipline, and that care historically has been relegated as the concern of women, working-class people, and ethnic minorities (Tronto, 2010). The literature also demonstrates that while male nurses tend to sign up for technology intensive care practices, like anaesthesia or intensive care (Mrayyan and Al-Faouri, 2008), female nurses and midwives tend to downplay or under communicate the technology dimension of their care practices (Dyb, 2009). In addition, women's careers are often more winding and interrupted than men's (Holth, 2012), and reduced gender inequalities require management control to support the agency of women (Myreteg, 2019). In order to prepare and recruit women into eHealth, it is important to generate new knowledge and search for insights about the career trajectories of women working with digital transformation in health care today.

This study investigates women who worked with the above-mentioned major transformation, aiming to understand who they are and where they came from. Our analysis identifies different types of trajectories that brought the women into eHealth transformations: some were "pushed into" working with eHealth, some used eHealth as an "escape route" from something else, while others "stumbled across" eHealth and decided to stay on. Below, we start by describing the background to the study before we present the three trajectories to eHealth, and finally we discuss the implications of our findings.

\section{METHOD}

Eight women, working as managers with the implementation of PAEHR process were interviewed. The in-depth interviews were about their career choices and background, and their experiences from working in eHealth. The researchers developed the interview template collaboratively and it included questions about working life, perceptions of gender at work and experiences from working in the PAEHR project. A formal document of consent was signed by the respondents. They were reminded that they could refrain from answering any specific question or choose to end the interview at any point in time, if so wished. To take part was voluntary. Participants were recruited with the help of a national organisation for eHealth services, and we used purposive sampling (Brown and Clarke, 2013; Bryman, 2008). 
The eight women interviewed came from six different regions of PAEHR implementation with our intention to provide a broader understanding of this process. All interviews were recorded, transcribed and analysed using thematic analysis (Braun and Clarke, 2013). We interpreted the statements made by the interviewees as constituting their realities and subjectivities (Brown \& Clarke, 2013). An informed consent was sent out and signed by all respondents, including information about anonymity, voluntariness and GDPR. The analysis was carried out collaboratively within the research group. Each respondent's answers were interpreted and coded, and the research team wrote the paper collaboratively. Citations in this paper have been made more readable.

\section{RESULTS}

The eight women interviewed in this study all worked with regional implementation of PAEHR. In this work they were guided by a national regulatory framework, a recommendation, on what information should be available online to patients. However, there is still great variety in what information a patient is provided within different regions, as the regions have implemented the regulatory framework differently, or as Hägglund and Scandurra (2017) concludes: "development and implementation of PAEHR in Sweden is based on local initiatives". One such difference is patients' access to psychiatric medical records online (Petersson and Erlingsdóttir, 2018a, 2018b). Furthermore, the teams in the different regions were set up differently, and the process of implementation was different in the different regions. The women interviewed came from six different regions in Sweden. They all worked in a management team of people with different roles in the implementation. The teams varied in size, but typically they consisted of 3-8 people with different roles and responsibilities. Parts of the work with implementation of PAEHR is technical, and includes standards for information sharing, interoperability issues between many different information systems where data is stored, security issues, and usability issues. All regions have their own mix of different IT systems that store information that needs to be extracted to the PAEHR online. These systems can be off-the-shelf systems or systems that the region has procured, and depending on the system the process of creating an interface to PAEHR is different. Other parts of the work with implementation are social, and are related to creating processes for maintenance of the system, external communication to users, discussions of new ways of working with different health care units, and internal communication related to the change process.

The eight women all had a background from health care, and two of them had also studied IT (Table 1). All of them were a part of the management team for the implementation project in the respective region, and they presented themselves using different job titles. Their actual tasks in the implementation project varied depending on the phase of the projects, and also depended on their expertise in relation to the expertise of their co-workers in their local team. All interviewed women chose to enter the health care field as their primary interest. Examples of their backgrounds were physician, medical secretary or nurse. None of them entered the field of eHealth services through a first degree in computer science or informatics, however two of them had developed their interest for IT through their encounter with eHealth that made them enter higher education programs in computer science or informatics later on in their career. Some describe themselves as interested in technology per se, but a large majority are more interested in the use of technology and its practical possibilities.

The analysis shows different types of trajectories that brought the women into eHealth transformations: The first illustrates women who were pushed into working with eHealth through their job description, the second shows women using eHealth as an escape route from health care work, and the last trajectory shows how women stumbled across eHealth and decided to stay on. These career trajectories are further presented below. 
Table 1. Overview of the tasks of the different managers, and their background and expertise

\begin{tabular}{|c|c|c|c|c|}
\hline Theme & No & Examples of task & Background and expertise & IT degree \\
\hline \multirow[t]{3}{*}{$\begin{array}{l}\text { Pushed into } \\
\text { eHealth }\end{array}$} & INF1 & $\begin{array}{l}\text { Work environment perspective, } \\
\text { patient security, development of } \\
\text { national regulatory framework }\end{array}$ & Physician, union representative & No \\
\hline & INF2 & $\begin{array}{l}\text { Health care strategies, business } \\
\text { developer }\end{array}$ & $\begin{array}{l}\text { Assistant nurse, nurse in emergency care, } \\
\text { extensive management expertise. }\end{array}$ & No \\
\hline & INF5 & $\begin{array}{l}\text { Product owner, investigator, team } \\
\text { leader }\end{array}$ & $\begin{array}{l}\text { Medical secretary, } \\
\text { information officer, health care } \\
\text { administration manager }\end{array}$ & No \\
\hline \multirow[t]{2}{*}{$\begin{array}{l}\text { eHealth as an } \\
\text { escape route }\end{array}$} & INF3 & $\begin{array}{l}\text { Technical decisions, implementatior } \\
\text { from a sociotechnical perspective, } \\
\text { risk analysis }\end{array}$ & $\begin{array}{l}\text { Medical secretary, } \\
\text { information officer }\end{array}$ & No \\
\hline & INF4 & $\begin{array}{l}\text { Education, support, communication, } \\
\text { risk analysis }\end{array}$ & $\begin{array}{l}\text { Assistant nurse, nurse, midwife, } \\
\text { administrator and manager, }\end{array}$ & No \\
\hline \multirow[t]{3}{*}{$\begin{array}{l}\text { Stumbled across } \\
\text { eHealth }\end{array}$} & INF6 & $\begin{array}{l}\text { Investigations, information structure } \\
\text { informatics generally, process } \\
\text { management, }\end{array}$ & $\begin{array}{l}\text { Medical secretary, } \\
\text { computer engineer, leadership and change } \\
\text { management }\end{array}$ & Yes \\
\hline & INF7 & $\begin{array}{l}\text { Change management, technical } \\
\text { decisions, risk analysis, } \\
\text { communication }\end{array}$ & $\begin{array}{l}\text { Physiotherapist and } \\
\text { IT developer }\end{array}$ & No \\
\hline & INF8 & $\begin{array}{l}\text { Business development, informatics } \\
\text { generally }\end{array}$ & Medical secretary, strategy officer & Yes \\
\hline
\end{tabular}

\subsection{Pushed into eHealth Through Taking on a Role}

Three of the interviewed women described that their trajectory to working with digitalisation came through taking on a role that included working with eHealth. These roles did not traditionally, or initially, include eHealth and it was not the women's active initiative to become involved in IT, but with the rise of digitalisation, eHealth has become a part various roles and positions. The first example of this is a physician who took on the assignment as a union representative (INF1). A union representative in Sweden traditionally works with social and physical work environment issues. She had no previous experience with IT, and there were no technical parts in her education. As a union representative, however, she started to work with digital transformations from a work environment perspective. "I just got into it [eHealth] as a part of being a union representative". During the interview she describes that her first impression of working with eHealth and PAEHR system was negative, that she was sceptical to the idea, and that she felt a strong resistance towards some of the services, such as the replacement of the physical meeting with written information about diagnoses in an ICT system: "Well, the first feeling was negative. Hmmm, it was quite a strong negative feeling". In her work she has since been involved in the implementation of the system, while carefully paying attention to the work environment of physicians.

The second example of a person being pushed into eHealth by taking on a role is INF2. This person describes that she is motivated by helping and meeting people, but also by changing health care when it comes to increased accessibility from the patient perspective. She does not see herself as someone that is interested in technology, but wants technology to be a vehicle for change. She describes her career as consisting of two phases, care and technology: "it was care for quite long, and now it has been IT quite a long time". However, she had not planned to move into eHealth and IT work. The main reason to the shift was due to her being offered a role that included IT implementation work, which is described by this quote: "it has not been planned, but it was interesting assignments that have made me change my career in that way". 
Informant INF5 got a new job as a manager in a health care clinic that included traditional management duties. After some time they were going to implement a new system at the clinic, and she became involved in this work. Since then she has continued to work with implementation of eHealth.

All three women illustrate how they were "pushed" into working with digitalization in their respective organizations without a particular intention of working with IT, however, they took on the challenge and through their active engagement with eHealth transformations they have established a work profile that included IT.

\section{2 eHealth as an Escape Route from Health Care Work}

Informant INF3 describes that she was headhunted by her former manager into working at the management office, which included working with eHealth. She chose to accept the position due to it being so boring to stay on working at the clinic when her former manager had changed jobs: "when he left his position it became very boring to stay at that place. Later he started working at the local medical management's office, and then he headhunted me so I followed him there. And then I was recruited to this IT center". After this job shift she has continued to work with eHealth for almost 15 years.

Informant INF4 started working in the nursing profession as an assistant nurse. She first studied to become a nurse, and later, to become a midwife. After this she moved on to working with eHealth. She describes this trajectory as a result of being displeased with the work conditions as a midwife - they did not fit with her life situation. The combination of having toddlers while working odd hours did not work out, so she moved on when she was offered a project employment at IT: "It was an escape from ... having to work nights and weekends and evenings."

For these two women, working with IT appeared as a solution for an otherwise dissatisfacting work situation.

\subsection{Stumbled Across eHealth and Decided to Stay On}

Three of the women who were interviewed described that they stumbled across eHealth and related work tasks already when they worked with caring tasks. Through this work they caught an interest and eventually found eHealth to be fascinating. Thus, once they had started working with eHealth transformations, they stayed on. Two of them (INF6 and INF8) became so interested that they later enrolled in IT related subjects (computer science and informatics) at university level. This also created a foundation for them to move on to the IT unit of the organisation, where they became managers.

One of these two women (INF6), really liked her job in health care, so she describes her moving on to something else not as an escape route, but as a trajectory to something that seemed even more interesting. She had always been very interested in technology, and liked her job as medical secretary but came to a point where she felt that she needed to do something different. "Well, [...] I am very interested in technology and I really liked my job as a medical secretary. But then I came to the point: What do I do next? What do I want to do in my life? [...] And then I stumbled across an information about engineering." This motivated her for enrolling in IT education herself, thus securing a platform for her continuous engagement in eHealth.

The third woman in this category (INF7) has no formal IT degree, but just as the other two, she stumbled across eHealth work and became very interested in this area. In this category, all women were satisfied with the previous work situation with caring tasks, which is a difference from the previous trajectory, but they were attracted to the IT field and wanted to carry on working there instead of in their former roles in health care.

\section{DISCUSSION AND CONCLUSION}

None of the women in our study came from a traditional computer science or informatics background, despite that the job they do is quite technical and requires technical competence. Instead, they all entered the field of eHealth coming from a background in health care - as physiotherapists, nurses, midwives or physicians. This study has identified three main routes to eHealth were the women (1) took on a specific role, which included the technological aspect, that they (2) escaped from what they experienced to be a poor work situation in health 
care (cf. Rudman et al, 2014), or that they (3) stumbled across the area by chance but was captured and stayed on.

Previous research has established that the work environment for nurses in health care is problematic (Hsu, 2016). Alarming research shows that among young nurses, every fifth nurse strongly intended to leave the profession five years after graduation, and the intention was associated with levels of burnout (Rudman et al., 2014). Thus, it is not surprising that nurses leave their profession to do something else, but it is interesting to find that some of them leave their caring tasks for IT work, by getting involved in tasks related to eHealth services.

Notably, none of the respondents in this study described the choice of working with eHealth as intentional and an active choice at the beginning of their career. Of the three identified trajectories, the last is the most positive one where they describe that they move to something better rather than the trajectory based on escaping something that is not working well. The third trajectory also lies close to an active choice. At least the women here describe how they were very interested in technology and IT services. A reason why the interviewed women did not actively choose technology as primary work might be that computer science is stereotyped as a masculine line of work (Flanagan, 2015), and might therefore be connected to a stereotype threat (cf. Bergeron et al., 2006). This mechanism could lead to these women constructing other types of explanations to why they got involved in the eHealth area. In this article we, however, only analyse the trajectories of women. This is a limitation. We do not know whether men would describe a more active choice, than these women did, to why they are involved in development of eHealth services.

Women are a key part of the workforce and research has highlighted the possibilities and values of maintaining a diverse workforce (Flanagan, 2015). The findings call for a better understanding of how transformation processes involve a combination of competences, and the need to be able to collaborate with people coming from different backgrounds. We also need to open up the discussion regarding stereotypes of men's and women's capabilities regarding technology and IT work (Schorr, 2019). Therefore, the findings also have implications for the educational system, and in particular suggests an effort is needed to avoid that pupils already at an early age in life identify women as less "suited" for technology work as future health care work also requires knowledge about technology. The findings further point to the need for adults to be able to study computer science or informatics later in life.

\section{ACKNOWLEDGEMENT}

This work was partly funded by NordForsk through the NordWit Centre of Excellence.

\section{REFERENCES}

Bergeron, D.M., Block, C.J., Echtenkamp, A., 2006. Disabling the able: Stereotype threat and women's work performance. Human performance 19, 133-158.

Braun, V., Clarke, V., 2013. Successful qualitative research: A practical guide for beginners. sage.

Bryman, A., 2008. Social Research Methods, 3rd ed. Oxford University Press, New York.

Cajander, Å., Grünloh, C., 2019. Electronic Health Records Are More Than a Work Tool: Conflicting Needs of Direct and Indirect Stakeholders, in: CHI 2019, May 4-9, 2019, Glasgow, Scotland. ACM, New York. https://doi.org/10.1145/3290605.3300865

Cajander, Å., Moll, J., Englund, S., Hansman, A., 2018. Medical Records Online for Patients and Effects on the Work Environment of Nurses., in: MIE. pp. 271-275.

Dixon, B.E., 2007. A Roadmap for the Adoption of e-Health. E-service Journal 5, 3-13.

Dyb, K., 2009. Jordmorskap og teknologi. Tidsskrift for kjønnsforskning 33, 176-193.

Erlingsdóttir, G., Lindholm, C., 2015. When patient empowerment encounters professional autonomy: The conflict and negotiation process of inscribing an eHealth service. Scandinavian journal of public administration 19, $27-48$.

Erlingsdottir, G., Lindholm, C., Ålander, T., 2014. eHealth services, patient empowerment and professional accountability-An empirical study on the changing patient-doctor relationship in the digital world, in: International EIASM Public Sector Conference. pp. 1-21. 
Eurostat, 2019. ICT specialists in employment [WWW Document]. URL https://ec.europa.eu/eurostat/statisticsexplained/index.php/ICT_specialists_in_employment (accessed 4.27.20).

Flanagan, J., 2015. Gender and the workplace: The impact of stereotype threat on self-assessment of management skills of female business students. Advancing Women in Leadership Journal 35, 166-171.

Grünloh, C., Cajander, Å, Myreteg, G., 2016. “The Record is Our Work Tool!”-physicians' framing of a patient portal in Sweden. Journal of medical Internet research 18, e167.

Grünloh, C., Myreteg, G., Cajander, Å, Rexhepi, H., 2018. "Why do they need to check me?” Patient participation through eHealth and the doctor-patient relationship: qualitative study. Journal of medical Internet research 20, e11.

Hägglund, M., Scandurra, I., 2009. Patients' Online Access to Electronic Health Records: Current Status and Experiences from the Implementation in Sweden., in: MedInfo. pp. 723-727.

Hennemann, S., Beutel, M.E., Zwerenz, R., 2017. Ready for eHealth? Health professionals' acceptance and adoption of eHealth interventions in inpatient routine care. Journal of health communication 22, 274-284.

Holth, L., 2012. Den raka och den krokiga vägen till ingenjörsyrket: Om rationella kvinnor och passionerade män. Segregationens seghet och dess föränderliga former: En vänbok till Lena Gonäs 25, 141-159.

Hoque, M.R., Bao, Y., Sorwar, G., 2017. Investigating factors influencing the adoption of e-Health in developing countries: A patient's perspective. Informatics for Health and Social Care 42, 1-17.

Hsu, M.-Y., 2016. A quality of working life survey instrument for hospital nurses. Journal of Nursing Research 24, 87-99.

Moll, J., Rexhepi, H., Cajander, Å Grünloh, C., Huvila, I., Hägglund, M., Myreteg, G., Scandurra, I., \AAhlfeldt, R.-M., 2018. Patients' Experiences of Accessing Their Electronic Health Records: National Patient Survey in Sweden. JMIR 20, e278. https://doi.org/10.2196/jmir.9492

Mrayyan, M.T., Al-Faouri, I., 2008. Nurses' career commitment and job performance: Differences between intensive care units and wards. Journal of Research in Nursing 13, 38-51.

Nilsson, L., Eriksén, S., Borg, C., 2016. The influence of social challenges when implementing information systems in a Swedish health-care organisation. Journal of nursing management 24, 789-797.

Okun, S., Wicks, P., 2018. DigitalMe: a journey towards personalized health and thriving. Biomedical engineering online $17,119$.

Regeringskansliet, R. och, 2017. För ett hållbart digitaliserat Sverige - en digitaliseringsstrategi [WWW Document]. Regeringskansliet. URL https://www.regeringen.se/informationsmaterial/2017/05/for-ett-hallbart-digitaliseratsverige---en-digitaliseringsstrategi/ (accessed 4.14.20).

Regeringskansliet, R. och, 2016. Vision e-hälsa 2025 [WWW Document]. Regeringskansliet. URL https://www.regeringen.se/informationsmaterial/2016/04/vision-e-halsa-2025/ (accessed 4.14.20).

Rudman, A., Gustavsson, P., Hultell, D., 2014. A prospective study of nurses' intentions to leave the profession during their first five years of practice in Sweden. International journal of nursing studies 51, 612-624.

Scandurra, I., Hägglund, M., Persson, A., LAAhlfeldt, R.-M., 2014. Disturbing or Facilitating? -On the Usability of Swedish eHealth Systems 2013., in: MIE. pp. 221-225.

Schorr, A., 2019. Pipped at the post: Knowledge gaps and expected low parental IT competence ratings affect young women's awakening interest in professional careers in information science. Frontiers in psychology 10, 968.

Socialstyrelsen, 2019. Statistik om legitimerad hälso- och sjukvårdspersonal 2018 samt arbetsmarknadsstatus 2017 [WWW Document]. Socialstyrelsen. URL https://www.socialstyrelsen.se/globalassets/sharepointdokument/artikelkatalog/statistik/2019-9-6311.pdf. (accessed 4.27.20).

Tronto, J.C., 2010. Creating caring institutions: Politics, plurality, and purpose. Ethics and social welfare 4, 158-171.

Walker, J., Leveille, S., Bell, S., Chimowitz, H., Dong, Z., Elmore, J.G., Fernandez, L., Fossa, A., Gerard, M., Fitzgerald, P., 2019. OpenNotes after 7 years: patient experiences with ongoing access to their clinicians' outpatient visit notes. Journal of medical Internet research 21, e13876.

Wass, S., Vimarlunda, V., 2018. I got 99 problems, and eHealth is one, in: MEDINFO 2017: Precision Healthcare Through Informatics: Proceedings of the 16th World Congress on Medical and Health Informatics. IOS Press, p. 258. 